\title{
Emergence of Ebola Virus Disease (EVD): Key Facts
}

\author{
*MM Rahman ${ }^{1}$, F Mehrin ${ }^{2}$ F Ahmed $^{3}$ \\ $1 *$ Prof. Dr. Md. Mahfuzar Rahman, Head, Department of community medicine, AKMMC \\ ${ }^{2}$ Dr. Farnaz Mehrin, Lecturer, Department of community medicine, AKMMC \\ ${ }^{3}$ Dr. Fahim Ahmed, Pblic Health Specialist \\ *Corresponding Author
}

\begin{abstract}
The modern emerging infection Ebola Virus Disease (EVD) is of global threat originates from Africa region. This is zoonotic and identified as human diseases or previously called Ebola hemorrhagic fever which is a highly fatal human illness where case fatality rate is found up to $90 \%$. The virus transmission begins from wild animals to human and then spreads within population through human to human. Fruit bats are found as natural host of Ebola virus. There is no specific treatment or vaccine available in the market so far, intensive supportive care is needed for severely ill patients. This paper highlights background information, problem statement, viral characteristics, mode of transmission, signs and symptoms, prevention \& vaccination. It also indicates possible actions towards prevention of transmission $\&$ personal protection.
\end{abstract}

Key Words: Ebola virus disease, zoonotic, global threat, Africa

\section{Introduction}

The first case of Ebola was reported on 26 August 1976, in Yambuku, a small rural village in Mongala District in northern Democratic Republic of the Congo. The first victim, and index case was a village school headmaster Mabalo Lokela, who toured an area near the Central African Republic border along the Ebola river between 12-22 August and died on 8 September1,2. Infections with Ebola viruses originating from Africa cause a severe disease in humans, The Ebola virus disease (EVD) have five species of the genus Ebolavirus (Filoviridae family) which have been identified from outbreak samples collected from humans and non-human primates: Zaïre ebolavirus (EBOV), Sudan ebolavirus, Reston ebolavirus, Taï Forest ebolavirus and Bundibugyo ebolavirus 3,4 . The viruses can survive number of days in liquid or dried materials and can be inactivated by UV radiation, gamma irradiation, and heating for 60 minutes at $60{ }^{\circ} \mathrm{C}$ or boiling for five minutes. It has found susceptible to sodium hypochlorite and disinfectants in particular 5,6 .

The risk of these virus infections depends on the type of virus contact with human cases. The incubation period varies from 2-21 days with an average 4-10 days. However, the Ebola virus will not be inactivated by freezing or refrigeration. The case-fatality ratio for Zaïre ebolavirus (EBOV) infections is found between $50-90 \% 7,8,9$.

AKMMC J 2015; 6(1): 35-37
These Ebola viruses are found highly transmissible by direct contact with infected blood, secretions, tissues, organs or other bodily fluids of dead or living infected persons. Transmission by air has not been documented yet. Person-to-person transmission is found as the principal mode for human outbreaks. It is documented that burial ceremonies also play a role in transmission as well10. It is observed for Marburg filovirus, and possible for Ebola viruses that it can transmit by sexual contact even up to seven weeks after clinical recovery11. Human transmission can also occur by contact with dead or living infected animals, e.g. primates (such as monkeys and chimpanzees), forest antelopes, duikers, porcupines and bats ${ }^{12}$. Nevertheless, bats are found most likely, but still unconfirmed reservoir for Ebola viruses ${ }^{13-15}$.

EVD early symptoms include flu-like illness, fever, muscle pain (myalgia), fatigue (weakness), headache and sore throat which are sudden onset. It is characterized by clinical manifestations and symptoms like; gastrointestinal (vomiting, diarrhoea, anorexia and abdominal pain), neurological (headaches, confusion), vascular (conjunctival/pharyngeal injections), cutaneous (maculopapular rash), and respiratory (cough, chest pain, shortness of breath), and exhaustion. In the first week, patients may deteriorate suddenly due to diarrhoea and vomiting and in more than $50 \%$ cases develops haemorrhagic manifestations like; bloody 
diarrhoea, nosebleeds, haematemesis, petechiae, ecchymosis and puncture bleedings after one week. However, few cases may develop profuse internal and external haemorrhages and disseminated intravascular coagulation 16,17. Death occurs as a result of tachypnoea, anuria, hypovolemic shock that corresponds to multi-organ failure. There is no specific treatment exists in EVD 18 . It is only and primarily supportive in nature i.e. balancing fluids and electrolytes to rehydrate only, anticoagulant therapy to prevent or control disseminated intravascular coagulation, maintenance of oxygen, pain management, and appropriate antimicrobials to treat secondary bacterial or fungal infections ${ }^{19-21}$. In many cases starting early treatment increases the chance of survival. However, many experimental treatments are under studies 22 .

\section{Conclusion: prevention and control should focus on: Controlling Reston ebolavirus in domestic animals}

Routine cleaning and disinfection of pig or monkey farms with sodium hypochlorite or other detergents as there is no animal vaccine. For any suspension immediate quarantine is advised. If an outbreak is suspected, the premises should be quarantined immediately. Active animal health surveillance is necessary to detect new cases towards providing early warning for veterinary and human public health authorities.

\section{Reducing the risk of Ebola infection in people}

By raising awareness and using protective measures by individuals. Handling animals with gloves and by protective cloths. Meat should be prepared and cooked adequately before consumption. Avoiding direct or close contact with infected patients and with their bodily fluids. Use of gloves and personal protective equipment, regular hand washing after visiting patients in hospital and community settings will help preventing person to person transmission. In addition, awareness of the people regarding nature of the disease, its outbreak and containment measures, including prompt burial of the dead can help as a protective measures for the people at large in an affected community.

Moreover, bio-security measures may help to limit transmission. Wearing protective clothing and hand washing may be helpful for the meat handlers in particular. Samples of bodily fluids and tissues from people should be handled with special care and caution ${ }^{23}$.

\section{Controlling infection in health-care settings}

As symptoms of EBV is non-specific and may not be possible to identify cases it is important to apply standard precautions for the health care providers irrespective of their diagnosis. Those precautions includes; basic hand wash, respiratory hygiene, use of personal protective equipment as appropriate, safe injection practices and safe burial practices etc. Staffs working in the laboratory needs training for handling such samples and be able to protect himself with appropriate equipment.

In addition, routine hand washing, avoiding close contact with dead or alive animals and consumption of bush meat can be considered as generic precaution measures for people travelling in West African countries towards preventing Ebola virus infection.

\section{References}

1. Hewlett, Barry; Hewlett, Bonnie (2007). Ebola, Culture and Politics: The Anthropology of an Emerging Disease. Cengage Learning. p. 103. Retrieved 2014-07-31.

2. "Ebola haemorrhagic fever in Zaire, 1976"Bull. World Health Organ. 1976; 56 (2): 271-93.

3. Emond RT, Evans B, Bowen ET, et al. A case of Ebola virus infection. Br Med J. 1977 Aug 27;2(6086):541-4.

4. Piercy TJ, Smither SJ, Steward JA, et al. The survival of filoviruses in liquids, on solid substrates and in a dynamic aerosol. J Appl Microbiol. 2010 Nov;109(5):1531-9.

5. Public Health Agency of Canada. Ebola virus. Pathogen Safety Data Sheet - Infectious substances [internet]. Public Health Agency of Canada.; 2010 [cited 2014 Mar 31]. http://www.phac-aspc.gc.ca/lab-bio/res/psds-ftss/ebolaeng.php

6. European Centre for Disease Prevention and Control. Risk assessment guidelines for diseases transmitted on aircraft. 2nd ed. Stockholm: ECDC; 2010. Available from: http://ecdc.europa.eu/en/publications/publications/1012_gui ragida_2.pdf

7. World Health Organization. A Guide for Shippers of Infectious Substances, 2013 [internet]. 2014 [cited 2014 Mar 22]. Available from: http:// www.who.int/ ihr/ infectious_substances/ en/.

8. Chepurnov AA, Chuev Iu P, P'Iankov O V, et al. [The effect of some physical and chemical factors on inactivation of the Ebola virus]. Vopr Virusol. 1995 Mar-Apr;40(2):74-6

9. European Centre for Disease Prevention and Control. ECDC fact sheet: Ebola and Marburg fever [internet]. ECDC; 2014 [cited 2014 Mar 20]. Available from: http:// www.ecdc.europa.eu/en/healthtopics/ebola_marburg_fevers/ pages/index.aspx. 
10. Bannister B. Viral haemorrhagic fevers imported into nonendemic countries: risk assessment and management. Br Med Bull. 2010;95:193-225.

11. World Health Organization. Ebola haemorrhagic fever - Fact sheet [internet]. WHO Media centre; 2012 [cited 2014 Mar20]. Availablefrom: http:// www.who.int/mediacentre/ factsheets/ fs103/en/.

12. Martini GA, Schmidt HA. [Spermatogenic transmission of the 'Marburg virus'. (Causes of 'Marburg simian disease')]. Klin Wochenschr. 1968 Apr 1;46(7):398-400.

13. Wood JL, Leach M, Waldman L, et al. A framework for the study of zoonotic disease emergence and its drivers: spillover of bat pathogens as a case study. Philos Trans R Soc Lond B Biol Sci. 2012 Oct 19;367(1604):2881-92.

14. Hayman DT, Yu M, Crameri G, et al. Ebola virus antibodies in fruit bats, Ghana, West Africa. Emerg Infect Dis. 2012 Jul;18(7):1207-9.

15. Pourrut X, Delicat A, Rollin PE, et al. Spatial and temporal patterns of Zaire ebolavirus antibody prevalence in the possible reservoir bat species. J Infect Dis. 2007 Nov 15;196 Suppl 2:S176-83.

16. Roddy P, Howard N, Van Kerkhove MD, et al. Clinical manifestations and case management of Ebola haemorrhagic fever caused by a newly identified virus strain, Bundibugyo, Uganda, 2007-2008. PLoS One. 2012;7(12):e52986.
MM Rahman, F. Mehrin

17. European Centre for Disease Prevention and Control. ECDC fact sheet: Ebola and Marburg fever [internet]. ECDC; 2014 [cited 2014 Mar 20]. Available from: http://www.ecdc.europa.eu/en/healthtopics/ebola_marburg_f evers/pages/index.aspx.

18. Choi JH, Croyle MA. "Emerging targets and novel approaches to Ebola virus prophylaxis and treatment". BioDrugs 2013; 27 (6): 565-83.

19. Bausch DG, Feldmann H, Geisbert TW, et al. "Outbreaks of Filovirus Hemorrhagic Fever: Time to Refocus on the Patient". The Journal of Infectious Diseases 2007; 196:22-23.

20. Jeffs B. "A clinical guide to viral haemorrhagic fevers: Ebola, Marburg and Lassa". Tropical Doctor 2006;36 (1): 1-4..

21. Nkoghé D, Formenty $\mathrm{P}$, Nnégué $\mathrm{S}$, et al. Comité International de Coordination Technique et Scientifique. "Practical guidelines for the management of Ebola infected patients in the field". Medecine tropicale : revue du Corps de sante colonial 2004; 64 (2): 199-204.

22. "Sierra Leone Is Epicenter of Ebola as Guinea Clinic Shut". 2014-06-08. Retrieved 2014-07-30

23. "Ebola virus disease Fact sheet $\mathrm{N}^{\circ} 103 "$. World Health Organization. 2014-03-01. Retrieved 2014-04-12. 